\title{
Electronic cigarettes in Canada: Prevalence of use and perceptions among youth and young adults
}

\author{
Christine D. Czoli, BSc, David Hammond, PhD, Christine M. White, MSc
}

\section{ABSTRACT}

OBJECTIVES: The goal of this study was to examine the prevalence and perceptions of electronic cigarette use among Canadian youth and young adults.

METHODS: A sample of 1,188 youth and young adults age 16-30 years were recruited from an online panel of Canadians in 2012. After viewing an image of an e-cigarette, respondents answered questions regarding their use and perceptions of e-cigarettes.

RESULTS: Close to half of respondents (43.4\%) had seen e-cigarettes advertised or for sale. A total of $16.1 \%$ reported trying an e-cigarette (5.2\% nonsmokers, $18.9 \%$ former smokers, and $34.5 \%$ current smokers), and $5.7 \%$ reported use in the past 30 days ( $0.8 \%$ non-smokers, $1.4 \%$ former smokers, and $15.0 \%$ current smokers). Compared to non-smokers, former smokers and current smokers were more likely to have tried e-cigarettes (OR=4.25 and $\mathrm{OR}=9.84$, respectively), and current smokers were more likely to have tried e-cigarettes than former smokers (OR=2.32). Current smokers were also more likely to be current users of e-cigarettes than both former smokers (OR=15.15) and non-smokers (OR=4.43). Smokers were interested in trying e-cigarettes to help them quit smoking (80.4\%), as a long-term replacement for cigarettes $(77.8 \%)$, or to use in places where they cannot smoke (80.9\%).

CONCLUSIONS: Awareness of e-cigarettes among surveyed youth and young adults is quite high. Almost one fifth (16.1\%) of participants reported trying e-cigarettes, with evidence of use among non-smokers.

KEY WORDS: Tobacco products; young adult; tobacco use cessation; harm reduction

lectronic cigarettes (e-cigarettes) are devices that emit vapour. ${ }^{1}$ E-cigarettes consist of a battery, an automatic or manual switch, an atomizer with a heating element, and a cartridge that contains a solution. Solutions, or "e-liquids" or "e-juices", typically contain propylene glycol or glycerol (or both), and can contain nicotine, flavours and additives. ${ }^{2}$ Both pre-filled and refillable e-cigarette cartridges are available for sale. ${ }^{3}$ In some models, the atomizer and cartridge are combined into a single unit - a cartomizer - which is intended to prevent leaking of the solution. ${ }^{2}$ Though e-cigarettes share physical and behavioural similarities with tobacco cigarettes - resembling them and being handled and used in much the same way - a key difference is that e-cigarettes do not contain tobacco and no combustion takes place. As a result, when e-cigarettes are smoked or "vaped", they emit vapour, but no smoke.

Invented in China in 2003, e-cigarettes entered American and European markets in 2006, and as of 2012, constituted a global market valued at $\$ 2$ billion. ${ }^{2}$ The e-cigarette market in the United States has grown rapidly, with sales tripling every year for the last few years. $^{2}$ In addition, all of the major American tobacco companies have now publicly announced their entry into the e-cigarette market. ${ }^{4}$ E-cigarettes are commonly marketed and sold over the Internet, and are becoming increasingly popular. ${ }^{2,5}$ In a study examining the popularity of e-cigarettes, electronic nicotine delivery systems queries in Canada and other countries increased dramatically, surpassing those of nicotine replacement therapy by late $2008 .^{6}$ The role of the Internet with respect to the issue of e-cigarettes is particularly relevant for youth and young adults, who tend to spend more time online than older segments of the population.

With respect to marketing, the main promise of e-cigarettes is that they are able to deliver nicotine as ably as cigarettes, thereby serving as a substitute product. However, this has not yet been demonstrated scientifically. ${ }^{7}$ E-cigarettes are also marketed with claims of health benefits, such as their lack of cancer-causing chemicals, the absence of first- or second-hand smoke, the fact that they will not stain teeth or damage skin, and their use as a quit aid. $^{7}$ According to several studies examining beliefs regarding e-cigarettes, self-reported perceptions and reasons for use among e-cigarette users mirror these marketing claims, as many users believe e-cigarettes to be healthier than regular cigarettes and report

\footnotetext{
Authors' Affiliation

School of Public Health and Health Systems, University of Waterloo, Waterloo, ON Correspondence: David Hammond, PhD, School of Public Health \& Health Systems, University of Waterloo, 200 University Avenue West, Waterloo, ON N2L 3G1, Tel: 519-888-4567, ext.36462, E-mail: dhammond@uwaterloo.ca

Sources of Funding: This research was supported by a grant from the Canadian Cancer Society Research Institute, as well as the Canadian Institutes of Health Research Training Grant in Population Intervention for Chronic Disease Prevention: A PanCanadian Program (Grant \#: 53893) (Czoli), the Ontario Tobacco Research Unit Ashley Studentship for Research in Tobacco Control (Czoli), the Ontario Graduate Scholarship (Czoli), the Propel Centre for Population Health Impact, a Canadian Institutes of Health Research New Investigator Award (Hammond), and a Canadian Cancer Society Research Institute Junior Investigator Research Award (Hammond).

Conflict of Interest: None to declare.
} 
using them for this reason. ${ }^{8-10}$ The majority of users believe that e-cigarettes can help people quit smoking, and many report positive changes in their health (e.g., less coughing, improved breathing, better physical fitness), and satisfaction with the use of e-cigarettes, particularly in reference to taste and flavour. ${ }^{8}$ Reporting of adverse events have varied: although serious events of pneumonia and chest pain were reported to the FDA in the US, the majority of selfreported side-effects were minor, including dryness or burning of mouth and throat, light-headedness, headaches, cough, and phlegm production. ${ }^{8}$

A review of e-cigarette studies indicated that awareness of e-cigarettes among youth was variable. For instance, only $10 \%$ of Korean youth were aware of e-cigarettes, while $86 \%$ of Polish students and $70 \%$ of young adults in the Midwestern US indicated they had ever heard of e-cigarettes. ${ }^{8}$ Reported rates of trial of e-cigarettes among youth were similarly variable, ranging from less than 1\% among male adolescents in the US in 2011 and among Korean adolescents in 2008, to $21 \%$ among Polish high school and university students in 2010-2011. ${ }^{8}$ A more recent study of Korean adolescents showed that e-cigarette trial had increased, with 9\% reporting having tried the product in 2011. ${ }^{11}$ Reported rates of current e-cigarette use among youth are consistently lower, at 1\% of young Midwestern US adults in 2010-2011, 2\% of North Carolina college students in 2009, and $7 \%$ of Polish high school and university students in 2010-2011. ${ }^{8}$ Research suggests that e-cigarette use is more common among males, smokers, and those with family or friends who smoke. ${ }^{8,11,12}$

In Canada, e-cigarettes containing nicotine are prohibited. ${ }^{13}$ However, despite this restriction, e-cigarettes with and without nicotine are widely available for sale and are becoming increasingly prominent in various types of retail stores. ${ }^{3}$. Anecdotal evidence suggests that the use of e-cigarettes in Canada is increasing; however, to date, there is limited research evidence. A single published study conducted in 2010-2011 found that approximately $40 \%$ of former and current adult smokers in Canada were aware of e-cigarettes and rates of trial and current use were $4 \%$ and $1 \%$, respectively. ${ }^{14}$

The current study sought to examine use of e-cigarettes among Canadian youth and young adults, including: 1) prevalence of e-cigarette use, 2) factors associated with e-cigarette use, and 3) perceptions of e-cigarettes.

\section{METHODS}

\section{Study design and protocol}

Data were collected as part of a cross-sectional survey conducted in Canada in July 2012. Following collection of socio-demographic information, participants were shown an image of an e-cigarette and were asked to respond to various questions regarding e-cigarettes (described below). The study received approval from the Office of Research Ethics at the University of Waterloo.

\section{Participants}

Youth and young adults age 16-30 years were recruited through Global Market Insite, Inc. (GMI), a commercial market research company with an online panel of Canadians. GMI panel members were sent an e-mail invitation with a link directly to the survey. Additional information on GMI's Canadian panel is available online. A total of 1,188 respondents were included in the analyses, after exclusion of participants with missing information regarding ethnicity $(n=10)$, education $(n=5)$, smoking status $(n=2)$, and reported trial of e-cigarettes $(n=6)$.

\section{Measures}

Demographic variables included gender, age, ethnicity, and education level. Ethnicity was classified as White or non-White (including South Asian, Chinese, Black, Filipino, Latin American, Arab, Southeast Asian, West Asian, Korean, Japanese, Aboriginal, or multi-racial). Education level was defined as the highest level of formal education completed at the time of the study. Education level categories included: Low (high school or less), Moderate (technical/trade school, community college, or some university, but no degree), and High (university degree or more).

"Current smokers" were defined as those who had smoked 100 cigarettes in their lifetime and had smoked in the last 30 days; "former smokers" had smoked 100 cigarettes in their lifetime but had not smoked in the last 30 days; and "non-smokers" had smoked less than 100 cigarettes in their lifetime. E-cigarette smoking status was determined by asking participants whether they had ever tried smoking an electronic or smokeless cigarette, and whether they had smoked an e-cigarette in the last 30 days. E-cigarette "never-users" had never tried an e-cigarette; e-cigarette "ever-users" had tried an e-cigarette, but had not smoked one in the last 30 days; and "current users" of e-cigarettes had tried an e-cigarette and had smoked one in the last 30 days.

Participants were asked three questions regarding their perceptions of e-cigarettes: "Is this product harmful to your health?", "Would you be interested in trying this product?", and "Should retail outlets, such as corner stores and gas stations, be allowed to sell this product?" Responses were provided on a scale from 1 "Not at all" to 10 "Extremely". Exposure to e-cigarettes was measured by asking participants: "Have you ever seen e-cigarettes advertised or for sale?", and purchasing of e-cigarettes by: "Have you ever purchased an e-cigarette?" Experiences of side-effects or adverse outcomes while using e-cigarettes was measured by asking e-cigarette ever-users: "Have you ever experienced any side-effects or adverse outcome(s) while using e-cigarettes?" E-cigarette everusers were also asked: "Would you recommend e-cigarettes to a friend?" Responses were provided on a scale from 1 "Not at all" to 10 "Extremely". Current smokers who reported at least some interest in trying e-cigarettes were asked to indicate their agreement with a list of potential reasons for using e-cigarettes: in places where you can't smoke cigarettes; for the times when you don't want to smoke around others; to help you cut back on the amount you smoke; to help you while you are trying to quit smoking; as a longterm replacement instead of cigarettes; as a cheaper alternative to cigarettes. Participants were asked to respond "Yes", "No" or "Maybe".

\section{Analysis}

Differences in the sample profile across smoking status were tested using chi-square tests for age, sex, ethnicity and education level. Two logistic regression models were conducted to examine factors associated with ever use and current use of e-cigarettes. Ever use and current use of e-cigarettes were measured as binary variables $(0,1)$, where 0 represented participants who had never used or 


\begin{tabular}{|c|c|c|c|c|c|}
\hline Characteristic & & $\begin{array}{c}\text { Non-smokers } \\
n=708 \\
\%(n)\end{array}$ & $\begin{array}{c}\text { Former smokers } \\
n=74 \\
\%(n)\end{array}$ & $\begin{array}{c}\text { Current smokers } \\
n=406 \\
\%(n)\end{array}$ & $\begin{array}{c}\text { Total } \\
n=1188 \\
\%(n)\end{array}$ \\
\hline \multirow[t]{4}{*}{ Age (years) } & Mean (SD) & $22.5(4.1)$ & $26.2(3.2)$ & $24.6(3.9)$ & $23.5(4.2)$ \\
\hline & $16-19$ & $28.7(203)$ & $4.0(3)$ & $14.5(59)$ & $22.4(265)$ \\
\hline & $20-24$ & $38.3(271)$ & 23.0 (17) & $31.0(126)$ & $34.8(414)$ \\
\hline & $25-30$ & $33.0(234)$ & $73.0(54)$ & $54.5(221)$ & $42.8(509)$ \\
\hline \multirow[t]{2}{*}{ Sex } & Male & $49.6(351)$ & $37.8(28)$ & $33.7(137)$ & $43.4(516)$ \\
\hline & Female & $50.4(357)$ & $62.2(46)$ & $66.3(269)$ & $56.6(672)$ \\
\hline \multirow[t]{2}{*}{ Ethnicity } & White & $63.3(448)$ & $82.4(61)$ & $71.2(289)$ & $67.2(798)$ \\
\hline & Non-White & $36.7(260)$ & $17.6(13)$ & 28.8 (117) & $32.8(390)$ \\
\hline \multirow[t]{3}{*}{ Education } & Low & $32.8(232)$ & $37.8(28)$ & $40.9(166)$ & $35.9(426)$ \\
\hline & Moderate & $40.2(285)$ & 41.9 (31) & 34.0 (138) & $38.2(454)$ \\
\hline & High & 27.0 (191) & $20.3(15)$ & $25.1(102)$ & $25.9(308)$ \\
\hline
\end{tabular}

* Education: Low = high school or less; Moderate = technical/trade school, community college, or some university but no degree; High = university degree or more.

Table 2. Prevalence of e-cigarette use by smoking status

\begin{tabular}{|c|c|c|c|c|c|c|c|c|c|}
\hline \multirow{3}{*}{\multicolumn{2}{|c|}{ Characteristic }} & \multicolumn{8}{|c|}{ Prevalence (\%) } \\
\hline & & \multicolumn{4}{|c|}{ Ever use of e-cigarettes } & \multicolumn{4}{|c|}{ Current use of e-cigarettes } \\
\hline & & $\begin{array}{c}\text { Non- } \\
\text { smokers } \\
n=708\end{array}$ & $\begin{array}{c}\text { Former } \\
\text { smokers } \\
n=74\end{array}$ & $\begin{array}{c}\text { Current } \\
\text { smokers } \\
n=406\end{array}$ & $\begin{array}{c}\text { Total } \\
n=1188\end{array}$ & $\begin{array}{c}\text { Non- } \\
\text { smokers } \\
n=708\end{array}$ & $\begin{array}{c}\text { Former } \\
\text { smokers } \\
n=74\end{array}$ & $\begin{array}{c}\text { Current } \\
\text { smokers } \\
n=406\end{array}$ & $\begin{array}{c}\text { Total } \\
n=1188\end{array}$ \\
\hline \multirow{4}{*}{$\begin{array}{l}\text { All } \\
\text { Age (years) }\end{array}$} & & 5.2 & 18.9 & 34.5 & 16.1 & 0.8 & 1.4 & 15.0 & 5.7 \\
\hline & 16-19 & 5.9 & $-^{*}$ & 33.9 & 12.5 & 0.5 & - & 10.2 & 2.6 \\
\hline & $20-24$ & 5.5 & - & 41.3 & 17.4 & 0.7 & - & 20.6 & 7.0 \\
\hline & $25-30$ & 4.3 & 14.8 & 30.8 & 16.9 & 1.3 & 0.0 & 13.1 & 6.3 \\
\hline \multirow[t]{2}{*}{ Sex } & Male & 4.8 & - & 33.6 & 13.2 & 0.9 & - & 13.1 & 4.3 \\
\hline & Female & 5.6 & 19.6 & 34.9 & 18.3 & 0.8 & 0.0 & 16.0 & 6.8 \\
\hline \multirow[t]{2}{*}{ Ethnicity } & White & 6.0 & 19.7 & 35.3 & 17.7 & 0.7 & 1.6 & 17.0 & 6.6 \\
\hline & Non-White & 3.8 & - & 32.5 & 12.8 & 1.2 & - & 10.3 & 3.8 \\
\hline \multirow[t]{3}{*}{ Education } & Low & 6.5 & - & 39.8 & 20.0 & 0.9 & - & 13.9 & 5.9 \\
\hline & Moderate & 5.6 & 19.4 & 37.7 & 16.3 & 0.7 & 0.0 & 16.7 & 5.5 \\
\hline & High & 3.1 & - & 21.6 & 10.4 & 1.0 & - & 14.7 & 5.8 \\
\hline
\end{tabular}

* Data not reported due to small sample size $(\mathrm{n}<30)$.

currently did not use e-cigarettes, and 1 represented participants who had tried or currently used e-cigarettes. Both models included age, sex, ethnicity, education level and smoking status as covariates. A second set of models were run for both outcomes examining all two-way interactions between the independent variables. Analyses were conducted using SPSS, Version 20 (IBM, Illinois).

\section{RESULTS}

\section{Sample characteristics}

Sample characteristics are shown in Table 1. Non-smokers, former smokers and current smokers differed significantly by age $\left(\chi^{2}=86.2\right.$, $\mathrm{p}<0.001)$, gender $\left(\chi^{2}=27.3, \mathrm{p}<0.001\right)$, and ethnicity $\left(\chi^{2}=15.6\right.$, $\mathrm{p}<0.001)$.

\section{Prevalence of e-cigarette use}

Prevalence of e-cigarette ever use and current use is summarized in Table 2. A total of $16.1 \%$ reported ever using an e-cigarette (5.2\% non-smokers, $18.9 \%$ former smokers, and $34.5 \%$ current smokers). Current use of e-cigarettes was reported by $5.7 \%$ ( $0.8 \%$ nonsmokers, $1.4 \%$ former smokers, and $15.0 \%$ current smokers).

E-cigarette ever-users $(n=191)$ were asked how likely they were (on a 10-point scale) to recommend e-cigarettes to a friend. The mean response was $7.29( \pm 2.908)$, and only $9.6 \%$ selected " 1 " or "Not at all". As well, among e-cigarette ever-users, 12.0\% reported experiencing side-effects or adverse outcomes, while 5.2\% responded "Don't know". Reported side-effects included headache, nausea, dizziness, dry mouth, sore throat, irritation of the throat, coughing, wheezing, and vomiting.

\section{Factors associated with e-cigarette use}

Table 3 shows the results of logistic regression analyses examining factors associated with e-cigarette use. As shown in Model 1, ever use of e-cigarettes was more common among respondents with low compared to those with high education $(\mathrm{OR}=2.02,95 \% \mathrm{CI}$ : 1.24 3.31; $\mathrm{p}=0.005)$. In addition, ever use of e-cigarettes was significantly more likely among former smokers than among non-smokers $(\mathrm{OR}=4.25,95 \% \mathrm{CI}: 2.11-8.56$; $\mathrm{p}<0.001)$, and significantly more likely among current smokers than among both former smokers $(\mathrm{OR}=2.32,95 \% \mathrm{CI}: 1.24-4.35 ; \mathrm{p}=0.009)$ and non-smokers $(\mathrm{OR}=9.84$, 95\% CI: 6.52-14.86; $\mathrm{p}<0.001)$. No interactions between the independent variables were significantly associated with ever use of e-cigarettes.

As shown in Model 2, current use of e-cigarettes was more common among respondents with high compared to those with low education $(\mathrm{OR}=4.29,95 \% \mathrm{CI}$ : $1.60-11.50 ; \mathrm{p}=0.004)$. Current use of e-cigarettes was also significantly more likely among current smokers than among both former smokers (OR=15.15, 95\% CI: 1.80-125.00; $\mathrm{p}=0.012)$ and non-smokers (OR=4.43, 95\% CI: 1.64 11.94; $\mathrm{p}=0.003)$. No interactions between the independent variables were significantly associated with current use of e-cigarettes.

\section{E-cigarette exposure}

A total of $43.4 \%$ reported having seen e-cigarettes advertised or for sale at one or more of the following locations: on the Internet (24.3\%); in Canada at a regular store, such as a corner store or gas station (23.1\%); outside of Canada (9.5\%); or elsewhere $(8.6 \%)$. A total of $13.8 \%$ reported ever having purchased an e-cigarette at one or more of the following locations: on the Internet $(2.0 \%)$; in 


\begin{tabular}{|c|c|c|c|c|}
\hline \multirow[t]{2}{*}{ Characteristic } & \multicolumn{2}{|c|}{$\begin{array}{c}\text { Model 1: } \\
\text { Ever use of e-cigarettes* }\end{array}$} & \multicolumn{2}{|c|}{$\begin{array}{c}\text { Model 2: } \\
\text { Current use of e-cigarettes* }\end{array}$} \\
\hline & OR $(95 \% \mathrm{Cl}) \dagger$ & p-value & OR $(95 \% \mathrm{CI}) \dagger$ & p-value \\
\hline \multicolumn{5}{|l|}{ Age (years) } \\
\hline $20-24$ vs. $16-19$ & $1.39(0.83-2.32)$ & 0.21 & $1.71(0.60-4.85)$ & 0.31 \\
\hline $25-30$ vs. $16-19$ & $0.95(0.57-1.59)$ & 0.84 & $1.18(0.41-3.36)$ & 0.76 \\
\hline $25-30$ vs. $20-24$ & $0.68(0.46-1.00)$ & 0.05 & $0.69(0.34-1.40)$ & 0.30 \\
\hline \multicolumn{5}{|l|}{ Sex } \\
\hline Female vs. male & $1.02(0.72-1.46)$ & 0.90 & $1.11(0.55-2.24)$ & 0.78 \\
\hline Ethnicity & & & & \\
\hline Non-White vs. White & $0.82(0.56-1.21)$ & 0.31 & $0.66(0.31-1.43)$ & 0.30 \\
\hline \multicolumn{5}{|l|}{ Education } \\
\hline Moderate vs. low & $0.89(0.60-1.31)$ & 0.54 & $1.30(0.63-2.69)$ & 0.48 \\
\hline High vs. low & $0.49(0.30-0.81)$ & 0.005 & $4.29(1.60-11.50)$ & 0.004 \\
\hline High vs. moderate & $0.56(0.35-0.90)$ & 0.02 & $3.29(1.26-8.62)$ & 0.15 \\
\hline \multicolumn{5}{|l|}{ Smoking status } \\
\hline Former smoker vs. non-smoker & $4.25(2.11-8.56)$ & $<0.001$ & $0.29(0.03-2.84)$ & 0.29 \\
\hline Current smoker vs. non-smoker & $9.84(6.52-14.86)$ & $<0.001$ & $4.43(1.64-11.94)$ & 0.003 \\
\hline Current smoker vs. former smoker & $2.32(1.24-4.35)$ & 0.009 & $15.15(1.80-125.00)$ & 0.012 \\
\hline
\end{tabular}

* $\mathrm{R}^{2}$ (Model 1$)=0.23 ; \mathrm{R}^{2}$ (Model 2$)=0.15$

$\dagger$ Odds ratios adjusted for all other variables in the table.

Canada at a regular store, such as a corner store or gas station (4.1\%); outside of Canada (0.5\%); or elsewhere (0.4\%).

\section{Perceptions of e-cigarettes}

Figure 1 shows mean reported perceptions of e-cigarettes on a 10-point scale by e-cigarette trial and smoking status. Among non-smokers and former smokers, perceptions of e-cigarette harm were lower among e-cigarette ever-users compared to never-users; however, this pattern was reversed for current smokers. When asked whether they would be interested in trying e-cigarettes, ever-users consistently reported greater interest than never-users. Most respondents offered moderate to high support when asked whether retail outlets should be allowed to sell e-cigarettes, with the exception of current smokers who were also never-users of e-cigarettes.

Current smokers reported at least some interest in trying e-cigarettes (by answering "Yes" or "Maybe", n=378) for the following reasons: to help cut back on the amount they smoked $(77.7 \%)$, as a long-term replacement instead of cigarettes (77.8\%), for the times when they don't want to smoke around others (78.8\%), to help them while they are trying to quit smoking (80.4\%), as a cheaper alternative to cigarettes $(80.7 \%)$, or in places where they can't smoke cigarettes (80.9\%).

\section{DISCUSSION}

The study findings highlight the accessibility and popularity of e-cigarettes among youth and young adults in Canada. Exposure to e-cigarettes in our sample was moderate with respect to the literature: almost half of our sample reported having seen e-cigarettes advertised or for sale. These findings are higher than those reported among youth in Korea, but lower than those from the United States and Poland. ${ }^{8}$ However, our findings are similar to levels of awareness recorded among current and former adult smokers in Canada, in which $40 \%$ were aware of e-cigarettes. ${ }^{14}$

Trial of e-cigarettes in our sample was higher than in the US and Korea, yet lower than in Poland. ${ }^{8}$ Although rates of trial were higher among former and current smokers, $5.2 \%$ of non-smokers in our sample reported trying e-cigarettes, indicating some interest among youth and young adults in experimenting with this new product. By comparison, 2011 data from Canadian youth age 15-19 years indicated that one in four $(24.3 \%)$ reported having tried a whole cigarette, $27 \%$ a cigarillo, and $17 \%$ a cigar. ${ }^{15}$ Although our study findings were drawn from a convenience sample, the reported trial of e-cigarettes warrants attention with respect to patterns of tobacco use among young adults.

Tobacco use emerged as an important and consistent predictor of e-cigarette use among Canadian youth and young adults. Current smokers were more likely than non-smokers and former smokers to use or to have used e-cigarettes, and former smokers were more likely than non-smokers to have tried e-cigarettes. These findings are consistent with existing research. ${ }^{8,12}$ In contrast, trial of e-cigarettes was not higher among males in our sample, as has been reported in other studies. ${ }^{8,12}$ In addition, although our analyses showed an interesting pattern with respect to level of education in that respondents with low were more likely than those with high education to have tried e-cigarettes, whereas this pattern was reversed for current use of e-cigarettes - such associations have not been reported in other studies. , $^{8,12}$

Previous studies indicate that most e-cigarette users report using e-cigarettes to reduce their tobacco cigarette consumption and/or as a smoking cessation tool. ${ }^{8}$ In the current study, smokers reported similar levels of interest (approximately 80\%) in trying e-cigarettes for a variety of reasons, including: to help cut back on the amount they smoked, as a long-term replacement instead of cigarettes, for the times when they don't want to smoke around others, to help them while they are trying to quit smoking, as a cheaper alternative to cigarettes, or in places where they can't smoke cigarettes. These findings are also consistent with e-cigarette marketing trends. ${ }^{7}$

Non-smokers who had not tried e-cigarettes reported little interest in trying the product, whereas the greatest interest was reported by current smokers who had tried e-cigarettes. High levels of interest in trying e-cigarettes among those who have previously tried the product generally suggest high levels of consumer appeal. Somewhat surprisingly, among those who had not tried e-cigarettes, reported interest among former smokers was very similar to that of current smokers. Interest among former smokers could signal an interest in e-cigarettes as a way to re-enter the nicotine market. Future research should examine these perceptions further in order to better understand how these 
Is this product harmful to your health?

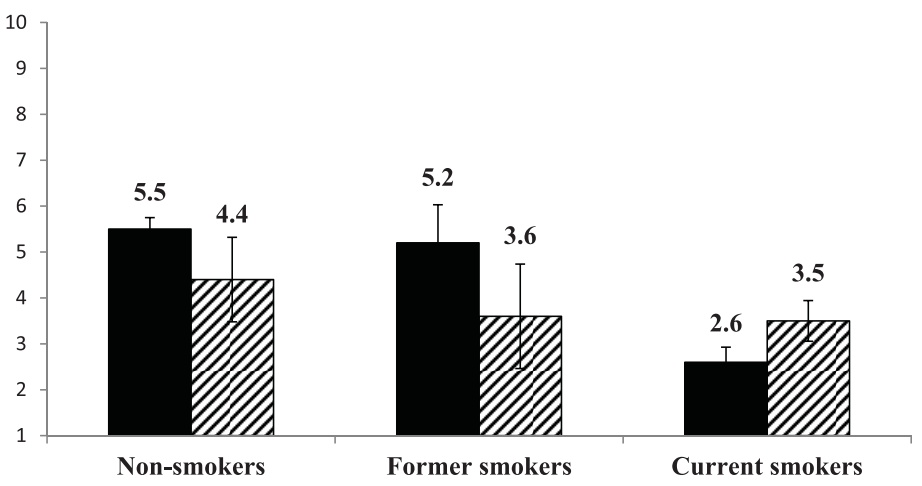

Would you be interested in trying this product?

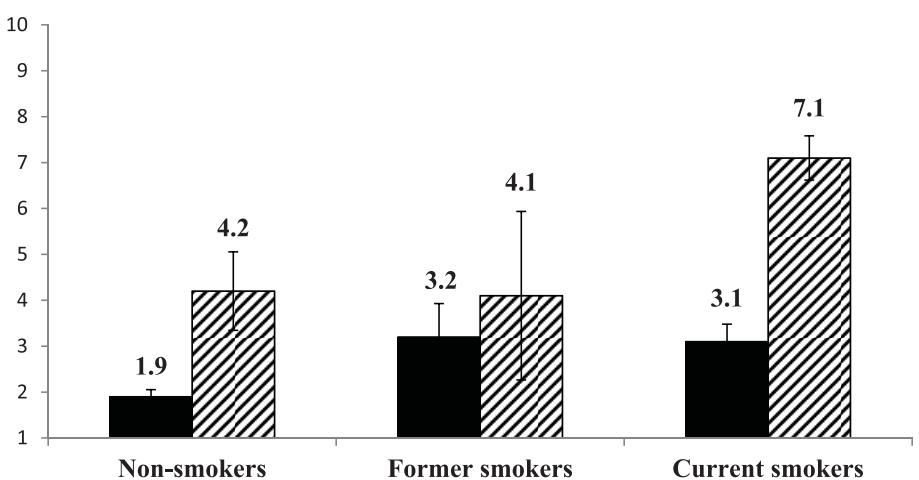

Should retail outlets be allowed to sell this product?

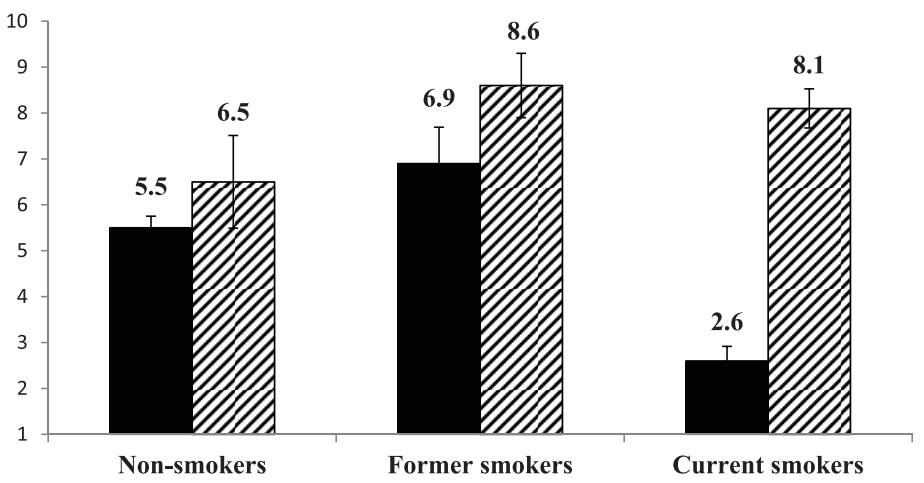

E-cigarette use Non-user Ever-user

Figure 1. Perceptions of e-cigarettes by e-cigarette ever use and smoking status

products are viewed and why they may be used by various subpopulations.

\section{Strengths and limitations}

The findings of this study are subject to various limitations. The cross-sectional design of the study does not allow for causal inferences to be drawn between tobacco use and use of e-cigarettes, or for the determination of the temporality of substance use. In addition, study participants were not recruited through random sampling. Therefore, although the sample profile is relatively diverse, it is not representative of the Canadian population. For example, our study sample had an unusually high smoking prevalence among females. Although this was adjusted for in the logistic regression models, it does not reflect national benchmarks.
For this reason, our findings may suffer from various biases and should be interpreted with caution.

\section{CONCLUSION}

The current study provides the first published evidence of e-cigarette use among Canadian youth and young adults. The findings indicate that almost one fifth of youth and young adults surveyed reported trying e-cigarettes, with evidence of use among non-smokers. The rapidity with which e-cigarette markets are growing and changing warrants greater surveillance of e-cigarette use. Such evidence would provide a better sense of the balance between the public health risks and benefits of e-cigarettes, which would be of great value for the development of public health policy. Future research should also examine the content of e-cigarettes in Canada to determine compliance with the restriction on nicotine.

\section{REFERENCES}

1. Cahn Z, Siegel M. Electronic cigarettes as a harm reduction strategy for tobacco control: A step forward or a repeat of past mistakes? J Public Health Policy 2011;32(1):16-31.

2. Etter J-F. The Electronic Cigarette: An Alternative to Tobacco? Geneva, Switzerland: Jean-Francois Etter, 2012;1-125.

3. Non-Smokers' Rights Association. The Buzz on E-Cigarettes, 2012. Available at: http://www.nsra-adnf.ca/cms/file/files/e-cig\%20Brochure\%20FINAL.pdf (Accessed February 1, 2013).

4. Felberbaum M. Marlboro maker Altria jumping into e-cigarettes. Available at: http://bigstory.ap.org/article/marlboro-maker-altria-jumping-e-cigarettes (Accessed June 26, 2013).

5. Noel JK, Rees VW, Connolly GN. Electronic cigarettes: A new 'tobacco' industry? Tobacco Control 2011;20:81.

6. Ayers JW, Ribisl KM, Brownstein JS. Tracking the rise in popularity of electronic nicotine delivery systems (electronic cigarettes) using search query surveillance. Am J Prev Med 2011;40(4):448-53.

7. Henningfield JE, Zaatari GS. Electronic nicotine delivery systems: Emerging science foundation for policy. Tobacco Control 2010;19(2):89-90.

8. Pepper JK, Brewer NT. Electronic nicotine delivery system (electronic cigarette) awareness, use, reactions and beliefs: A systematic review. Tobacco Control 2013;0:1-10. doi: 10.1136

9. Etter J, Bullen C. A longitudinal study of electronic cigarette users. Addict Behav 2013, Epub Oct30, doi: 10.1016

10. Kralikova E, Novak J, West O, Kmetova A, Hajek P. Do e-cigarettes have the potential to compete with conventional cigarettes? Chest 2013;144(5):1609-14.

11. Lee S, Grana RA, Glantz SA. Electronic cigarette use among Korean adolescents: A cross-sectional study of market penetration, dual use, and relationship to quit attempts and former smoking. J Adolesc Health 2013, Epub Nov22, doi: 10.1016.

12. Sutfin EL, McCoy TP, Morrell HER, Hoeppner BB, Wolfson M. Electronic cigarette use by college students. Drug and Alcohol Depend 2013;131:214-21.

13. Health Canada. Health Canada advises Canadians not to use electronic cigarettes, 2009. Available at: http://www.hc-sc.gc.ca/ahc-asc/media/ advisories-avis/ 2009/2009 53-eng.php (Accessed March 1, 2013).

14. Adkison SE, O'Connor RJ, Bansal-Travers M, Hyland A, Borland R, Yong H, et al. Electronic nicotine delivery systems: International Tobacco Contro Four-Country Survey. Am J Prev Med 2013;44(3):207-15.

15. Reid JL, Hammond D, Burkhalter R, Rynard VL, Ahmed R. Tobacco Use in Canada: Patterns and Trends, 2013. Available at: http://www.tobaccoreport.ca/2013/ (Accessed March 22, 2013).

Received: July 3, 2013

Accepted: January 18, 2014

\section{RÉSUMÉ}

OBJECTIF : L'objectif de cette étude était d'examiner la prévalence de I'utilisation de la cigarette électronique ainsi que sa perception chez les jeunes et les jeunes adultes canadiens.

MÉTHODE : Un échantillon de 1188 jeunes et jeunes adultes âgés de 16 à 30 ans a été recruté en 2012 à partir d'un panel en ligne de Canadiens. Après avoir visionné une image de e-cigarette, les participants répondaient à des questions relatives à leur utilisation et à leurs perceptions des e-cigarettes. 


\section{ELECTRONIC CIGARETTES IN CANADA}

RÉSULTATS : Quasiment la moitié des participants (43,4 \%) avaient déjà vu des e-cigarettes en vente ou des publicités relatives à des e-cigarettes. Un total de 16,1 \% ont indiqué avoir déjà essayé la e-cigarette (5,2 \% de non-fumeurs, $18,9 \%$ d'anciens fumeurs et $34,5 \%$ de fumeurs), et 5,7 \% ont rapporté une utilisation au cours des 30 derniers jours $(0,8 \%$ de nonfumeurs, 1,4 \% d'anciens fumeurs, et 15,0 \% de fumeurs). Les anciens fumeurs et les fumeurs étaient davantage susceptibles d'avoir déjà essayé la e-cigarette $(\mathrm{OR}=4,25$ et $\mathrm{OR}=9,84$, respectivement) par rapport à des non-fumeurs, et les fumeurs étaient davantage susceptibles d'avoir déjà essayé la e-cigarette que des anciens fumeurs $(O R=2,32)$. Les fumeurs étaient également davantage susceptibles d'être des utilisateurs de e-cigarettes que les anciens fumeurs $(O R=15,15)$ ou que les non-fumeurs $(\mathrm{OR}=4,43)$. Les fumeurs étaient intéressés par la e-cigarette comme une aide pour arrêter de fumer (80,4\%), comme un substitut à long terme aux cigarettes (77,8 \%), ou pour une utilisation dans des lieux nonfumeurs $(80,9 \%)$

CONCLUSIONS : Les e-cigarettes sont relativement bien connues parmi les jeunes et les jeunes adultes interrogés. Quasiment 1 participant sur $5(16,1 \%)$ rapporte avoir déjà essayé la e-cigarette, avec une utilisation rapportée chez les non-fumeurs.

MOTS CLÉS : produits dérivés du tabac; jeunes adultes; arrêt du tabac; réduction des risques sanitaires 